\title{
Literasi Keuangan, Teknologi Sistem Informasi, Pengendalian Intern dan Kualitas Laporan Keuangan UMKM
}

\author{
Hermi Sularsih ${ }^{1}$ \\ Program Studi Akuntansi \\ Sekolah Tinggi Ilmu Ekonomi Gempol, \\ Indonesia
}

\author{
Sukarno Himawan Wibisono ${ }^{2}$ \\ Fakultas Ekonomi \\ Universitas Tribhuwana Tunggadewi \\ Malang, Indonesia
}

Surel : hermisularsihstieg@gmail.com

ABSTRAK

Tujuan riset ini adalah untuk menjelaskan bagaimana literasi keuangan, teknologi sistem informasi, dan pengendalian intern pada kualitas laporan keuangan di era revolusi industri. Penelitian menggunakan metode kuantitatif diskriptif sebanyak 437 UMKM di Kabupaten Pasuruan dan analisis regresi berganda dengan data primer dan purposive sampling sebagai metode pemilihan sampel. Hasil riset ini menunjukan bahwa literasi keuangan $\left(X_{1}\right)$, teknologi sistem informasi $\left(X_{2}\right)$, berpengaruh terhadap kualitas laporan keuangan UMKM di era revolusi 4.0 sedangkan untuk pengendalian intern $\left(X_{3}\right)$ berpengaruh namun tidak signifikan pada kualitas laporan keuangan UMKM di era revolusi 4.0.

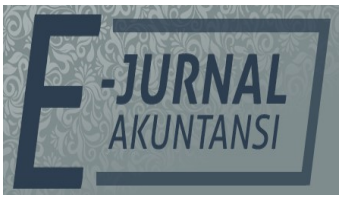

e-ISSN 2302-8556

Vol. 31 No. 8

Denpasar, Agustus 2021 Hal. 2028-2040

DOI:

10.24843/EJA.2021.v31.i08.p12

Kata Kunci: Literasi Keuangan; Teknologi Sistem Informasi; Pengendalian Interen; Kualitas.

PENGUTIPAN:

Sularsih, H., \& Wibisono, S.H.

(2021). Literasi Keuangan, Teknologi Sistem Informasi,

Pengendalian Intern dan

Financial Literacy, Information System Technology, Internal Control and Quality of MSME Financial Reports

\section{ABSTRACT}

The purpose of this research is to explain how financial literacy, information system technology, and internal control on the quality of financial reports in the era of the industrial revolution. The study used a descriptive quantitative method of 437 MSME in Pasuruan Regency and multiple regression analysis with primary data and purposive sampling as the method of selecting samples. The results of this research indicate that financial literacy $\left(X_{1}\right)$, information system technology $\left(X_{2}\right)$, have an effect on the quality of MSME financial reports in the revolutionary era 4.0, while internal control $\left(X_{3}\right)$ has an effect but is not significant on the quality of MSME financial reports in the revolutionary era 4.0.
Kualitas Laporan Keuangan UMKM. E-Jurnal Akuntansi, 31(8), 2028-2040

RIWAYAT ARTIKEL: Artikel Masuk: 22 Maret 2021 Artikel Diterima: 24 Agustus 2021

Keywords: $\quad$ Financial Literacy; Information Systems Technology; Internal Controls; Quality.

Artikel dapat diakses : https://ojs.unud.ac.id/index.php/Akuntansi/index 


\section{PENDAHULUAN}

Agenda 2030 PBB untuk Pembangunan berkelanjutan bertujuan peningkatan pertumbuhan ekonomi yang inklusif pada umkm melalui layanan keuangan (Yang \& Zhang, 2020). Bagaiamana dengan kesiapan UMKM yang ada di Indonesia terhadap apa yang menjadi agenda pada tahun 2030 oleh PBB tersebut. Tentunya hal ini bagi UMKM agar mampu menghadapi agenda PPB dengan pembukuan yang memadai, sehingga pengusaha pada UMKM dapat memenuhi untuk persyaratan dalam mengajukan kredit, dengan membuat laporan keuangan (Mukoffi \& Sulistiyowati, 2019). Selain agenda PBB tahun 2030, UMKM di Indonesia masih harus berhadapan dengan era revolusi industri 4.0 di mana UMKM dituntut harus mampu mengahadapi era revolusi ini. Hermi dan Nasir (2020), bahwa dalam rangka menghadapi era revolusi industri 4.0 perlu adanya strategi dan penguatan akan kualitas laporan keuangan UMKM. Kualitas laporan keuangan sebagai bukti penting bagi ekonomi yaitu potensi untuk mengurangi asimetri informasi dengan kreditornya melalui pelaporan keuangan yang lebih berkualitas Bauwhede et al., (2015). Konsisten dengan pandangan tradisional bahwa informasi asimetris atau tidak lengkap membatasi akses ke dana eksternal, hasil menunjukkan bahwa jumlah dan kualitas informasi laporan keuangan berhubungan positif dengan leverage usaha kecil menengah Caneghem, (2012).

Dampak penerapan standar akuntansi keuangan akan memberikan kemudahan akses modal dari perbankan sebagai indikasi akan kualitas laporan keuangan. (Rahmawati \& Puspasari, 2017). Sebagian besar pemilik UMKM tidak menerapkan standar laporan keuangan yang berlaku, sehingga dapat meyebabkan kebangkrutan terhadap usahanya karena tidak mampu dalam pengelolaan keuangan secara efektif dan benar (Putra, 2018). Namum Sistem serta teknologi data/informasi sangat berfungsi dalam bidang akuntansi guna pengambilan akan keputusan, maka sistem serta teknologi data atau informasi akuntansi dengan meningkatkan kinerja dalam organisasi serta sekalian sanggup menghindari serta mengetahui kesalahan dalam kegiatan pembedahan industri/ organisasi (Hanifah et al., 2020). Untuk akuntansi, maka sistem proses data akuntansi dengan berbasis digital telah di aplikasikan di bermacam industri, lembaga, ataupun pemerintahan, sebagai kemudahan untuk seluruh akuntan guna memperoleh data yang bisa dipakai sebagai dasar untuk pengambilan keputusan, namum teknologi sIstem informasi sangat susah diterapkan oleh UMKM. Selain itu pengendalian internal merupakan prediktor yang signifikan untuk akses ke pembiayaan pinjaman komersial (Bukenya, 2012). Tujuan dari riset untuk mengetahui literasi keuangan, teknologi sistem informasi, dan pengendalian intern apakah berpengaruh pada kualitas laporan keuangan, riset ini menarik untuk di teliti karena banyak peneliti melakukan penelitian pada usaha kecil menengah pada kualitas laporan keuangan, sedangkan riset terhadap UMKM tentang kualitas laporan keuangan dalam menghadapi era revolusi industry 4.0 serta kesiapan menghadapi agenda PBB tahun 2030 dalam upaya ke pelayanan keuangan, maka peneliti akan melihat akan kesiapan umkm dari sisi literasi keuangan, teknologi sistem informasi, dan pengendalian intern dimana yang sampai saat ini masih tidak diperdulikan oleh UMKM.

Banyak para pelaku UMKM yang belum menyadari begitu pentingnya laporan keuangan bahkan para pelaku umkm masih banyak yang tidak 
memahami akuntansi meskipun pemerintah telah menerbitkan SAK-EMKM dalam rangka mempermudah untuk meyusun laporan keuanganya. Sucuahi, (2013) Secara keseluruhan, tingkat literasi keuangan pengusaha mikro tergolong sedang yang menunjukkan pengelolaan keuangan sumber daya mereka tidak begitu mengesankan. Semakin menantang seiring dengan maraknya penerapan financial technology, khususnya di Indonesia, diperlukan literasi keuangan dengan baik untuk para calon wirausaha dalam mempersiapkan start upnya maupun bagi para wirausaha dalam menjalankan usahanya (Hatammimi \& Krisnawati, 2018). Gupta \& Kaur, (2014) Literasi keuangan menjadi jauh lebih penting setelah terjadinya financial distress dan menjadi prasyarat yang bertujuan untuk menghind ari krisis keuangan dengan mencapai stabilitas keuangan. Adapun demensi yang digunakan dalam leterasi keuangan yang digunakan oleh penelitian (Aribawa, 2016). Penelitian yang dilakukan Daniel et al., (2002) menunjukkan bahwa evaluasi ahli kualitas pelaporan keuangan lebih kuat terkait dengan penilaian mereka terhadap karakteristik kualitas pelaporan yang mendasari (misalnya, relevansi) yang dianut dalam kerangka Pernyataan Konsep Akuntansi Keuangan No. 2 daripada evaluasi literasi. (Anggraeni, 2015) melakukan penelitian yang hasil dari riset akan pengelolaan keuangan dipengaruhi oleh rendahnya tingkat literasi akan keuangan oleh pemilik, hal ini dapat dilihat dari sikap pemilik usaha terhadap laporan keuangan dimana hanya mencatat penerimaan dan pengeluaran keuangan usaha tanpa melakukan penyimpanan bukti dokumen pendukung. Nugrahaningtyasa (2020) hasil penelitian yang dilakukan menunjukkan kualitas keuangan dipengaruhi secara positif oleh literasi keuangan, berdasarkan penelitian tersebut hipotesis penelitian.

$\mathrm{H}_{1}$ : Terdapat Pengaruh Literasi Keuangan terhadap Kualitas Laporan Keuangan.

Mosteanu \& Faccia, (2020), berdasarkan kenyataan bahwa keuangan memainkan peran penting dalam setiap perekonomian. Saat ini, keuangan harus mampu mengelola dan beradaptasi dengan Era Digital.Teknologi informasi telah menjadi sumber daya bisnis yang penting karena ketiadaannya dapat mengakibatkan keputusan yang buruk dan akhirnya kegagalan bisnis (Dandago \& Rufai, 2014). Dampak teknologi informasi (TI) pada sistem akuntansi. Dampak terbesar yang dibuat TI pada akuntansi adalah kemampuan perusahaan untuk mengembangkan dan menggunakan sistem terkomputerisasi untuk melacak dan mencatat transaksi keuangan. Jaringan TI dan sistem komputer telah mempersingkat waktu yang dibutuhkan oleh akuntan untuk menyiapkan dan menyajikan informasi keuangan kepada manajemen. Sistem ini memungkinkan perusahaan untuk membuat laporan individual dengan cepat dan mudah untuk pengambilan keputusan manajemen. Kemampuan lain dari sistem akuntansi terkomputerisasi adalah Peningkatan Fungsi, Peningkatan Akurasi, Pemrosesan Lebih Cepat, dan Pelaporan Eksternal yang Lebih Baik (Ghasemi et al., 2011). Sistem akuntansi keuangan daerah (SAKD) memediasi pengaruh kompetensi pada Sumber Daya Manusia (SDM), namum kualitas akan laporan keuangan tidak dipengaruhi secara signifikan oleg pemanfaatan teknologi informasi pada pemerintah daerah Kabupaten Labuhanbatu (Muda et al., 2017). Penelitian yang dilakukan Gasperz, (2019) hasil dari riset menunjukkan pemanfaatan akan teknologi data/ informasi tidak berpengaruh pada kualitas laporan keuangan, 
sedangkan menurut Aniftahudin et al., (2016) mengatakan bahwa teknologi informasi terdapat pengaruh positif pada kualitas pelaporan keuangan, daerah, dan pemahaman akuntansi, sistem akuntansi keuangan pemerintah daerah, teknologi informasi mempengaruhi pelaporan keuangan yang berkualitas, maka berdasarkan penelitian tersebut hipotesisnya sebagai berikut.

$\mathrm{H}_{2}$ : Terdapat Pengaruh Teknologi Sistem Informasi Terhadap Kualitas Laporan Keuangan.

Sistem pengendalian intern yang efektif tidak hanya memfasilitasi evaluasi kinerja perusahaan tetapi juga dapat membatasi tingkat risiko. Jadi, untuk para pemimpin organisasi bisnis keluarga, sistem pengendalian internal adalah alat penting dalam menentukan keberhasilan maupun kegagalan sebagai bentuk perbedaan serta suksesi atau kadaluwarsa (Suárez, 2017). Ketika perusahaan mengalami kelemahan pengendalian internal material, pemberi pinjaman mengurangi penggunaan perjanjian keuangan dan ketentuan harga kinerja berbasis pada rasio keuangan dan alternatif sebagai penggantinya, seperti perlindungan harga dan keamanan dan ketentuan penetapan harga kinerja berbasis peringkat kredit. peneliti juga menemukan bahwa perubahan dalam desain kontrak utang mengikuti kelemahan pengendalian internal secara substansial berbeda dari yang berikut penyajian kembali, di mana pemberi pinjaman memberlakukan pemantauan yang lebih ketat terhadap tindakan manajer, tetapi tidak mengurangi penggunaan nomor laporan keuangan (Costello \& Regina, 2011). Untuk mengukur pengendalian internal berdasarkan penelitian yang dilakukan (Faishol \& Lamongan, 2016) Sistem pengendalian intern yang efektif bukan hanya memfasilitasi evaluasi kinerja perusahaan tetapi juga dapat membatasi tingkat risiko. Jadi, untuk para pemimpin organisasi bisnis keluarga, sistem pengendalian internal adalah alat penting dalam penentu keberhasilan dan kegagalan sebagai perbedaan. riset yang dilakukan Aditya \& Surjono, (2017) menghasilkan akan kualiats keuangan daerah dipengaruhi secara kuat dan positif oleh pelaksanaan sistem pengendalian intern berdasarkan penelitian tersebut maka hipotesis penelitian.

$\mathrm{H}_{3}$ : Terdapat Pengaruh Pengendalian Intern Terhadap Kualitas Laporan Keuangan.

\section{METODE PENELITIAN}

Metode dalam riset ini adalah kuantitatif dengan analisis data deskriptif'. Metode pengumpulan informasi yang digunakan merupakan wawancara, observasi, study pustaka serta kuesioner. Populasi riset ini Usaha Mikro Kecil serta Menengah di Kabupaten Pasuruan yang tersebar di 24 Kecamatan dengan jumlah 2.185 usaha makana dan minuman. Pengambilan sampel untuk riset (Arikunto, 2010), jika subjeknya memiliki kurang 100 orang maka semuanya diambil, jika subjeknya lebih dari 100 orang perlu di gunakan 10-15 persen juga bisa 20-25 persen maupun lebih. Dari populasi yang digunakan 20 persen dari populasi maka jumlah populasi 20 persen $\times 2.185=437$ responden. Peneliti ini menggunakan 20 persen karena penentuan ukuran pada jumlah sampel terdapat 2.185 UKM bidang usaha Makanan sehingga tidak mungkin untuk diambil keseluruhan menjadi sampel dan UMKM terwakili untuk menjadi sampel. Adapun instrumen yang digunakan dalam riset berupa kuesioner dengan uji 
validitas bantuan software komputer yaitu SPSS Versi 26. Penelitian ini menggunakan uji sttistik deskriptif, uji norma, uji, multikolineritas, uji heteroskedastisitas, uji autokorelasi, uji koefisien determinasi, uji regresi linier berganda, Uji F dan uji t. Model analisis regresi linier berganda yang digunakan dalam penelitianini adalah sebagai berikut.

$Y=\alpha+\beta_{1} X_{1}+\beta_{2} X_{2}+\beta_{3} X_{3}+\varepsilon$

Keterangan :

$$
\begin{array}{ll}
\mathrm{Y} & =\text { Kualitas Laporan Keuangan } \\
\mathrm{a} & =\text { Nilai kostanta } \\
\beta 1 & =\text { Koefisien regresi dari literasi keuangan } \\
\beta 2 & =\text { Koefisien regresi dari teknologi sistem informasi } \\
\beta 3 & =\text { Koefisien regresi dari pengendalian intern } \\
\mathrm{X}_{1} & =\text { Literasi Keuangan } \\
\mathrm{X}_{2} & =\text { Teknologi Sistem Informasi } \\
\mathrm{X}_{3} & =\text { Pengendalian Intern } \\
\varepsilon & =\text { Standar eror }
\end{array}
$$

\begin{tabular}{|c|c|c|c|}
\hline Variabel & Definisi Operasional & Indikator & Skala \\
\hline Kualitas Laporan & Suatu kondisi keuangan dan hasil & 1.Relevan & \multirow{18}{*}{$\begin{array}{l}\text { Skala } \\
\text { Likert } \\
1-5\end{array}$} \\
\hline Keuangan & suatu usaha perusahaan pada saat & 2.Andal & \\
\hline$(\mathrm{Y})$ & tertentu atau jangka waktu & 3.Dapat & \\
\hline (Aniftahudin et al., & tertentu. & dibandingkan & \\
\hline 2016) & & 4.Dapat dipahami & \\
\hline Literasi Keuangan & Pengetahuan pengelolaan & 1.Pengetahun & \\
\hline$\left(\mathrm{X}_{1}\right)$ & keuangan untuk mencapai & umum keuangan & \\
\hline \multirow[t]{3}{*}{ (Aribawa, 2016) } & \multirow[t]{3}{*}{ kesejahteraan. } & $\begin{array}{l}\text { 2. Tabungan dan } \\
\text { pinjaman }\end{array}$ & \\
\hline & & 3.Asuransi & \\
\hline & & 4.Investasi & \\
\hline \multirow{4}{*}{$\begin{array}{l}\text { Teknologi Sistem } \\
\text { Informasi }\left(X_{2}\right) \\
\text { (Widarsono, 2013) }\end{array}$} & \multirow{4}{*}{$\begin{array}{l}\text { Teknologi untuk mengolah data } \\
\text { dalam berbagai cara untuk } \\
\text { menghasilkan informasi yang }\end{array}$} & 1.System Quality & \\
\hline & & 2.Information & \\
\hline & & quality & \\
\hline & & $\begin{array}{l}\text { 3.System use } \\
\text { 4.User satisfaction }\end{array}$ & \\
\hline Pengendalian & Proses yang dijalankan untuk & 1.Lingkungan & \\
\hline Intern $\left(X_{3}\right)$ & menyediakan jaminan memdai & 2.Penilaian resiko & \\
\hline (Faishol \& & bahwa tujuan pengendalian & 3.Kegiatan & \\
\hline Lamongan, (2016) & $\begin{array}{l}\text { mengamankan aset, mengolah } \\
\text { pencatatan,informasi akurat. }\end{array}$ & pengendalian & \\
\hline
\end{tabular}

Definisi operasional dan skala pengukurannya yang digunakan dalam penelitian ini dijelaskan pada Tabel 1, berikut.

Tabel 1. Definisi Operasional Variabel

Sumber: Data Penelitian, 2021

\section{HASIL DAN PEMBAHASAN}

Validitas menunjukkan dimana alat pengukur akan dipergunakan dalam menilai terhadap yang diukur, yaitu dikorelasikan pada item pernyataan dengan cara menskor total individu. Uji validitas dalam riset ini digunakan program SPSS Versi 24. Dalam riset ini uji validitas pada 437 responden. Dalam pengambilan keputusan yang menunjukkan nilai $\mathrm{r}_{\text {hitung }}$ Corrected Item - Total Correlation $>\mathrm{r}_{\text {tabel }}$ 
sebesar 0,196, untuk df $=437-4=433=0,05$ maka item pada pernyataan ini dinyatakan valid serta sebaliknya. Hasil output uji validitas variabel $x$ dan y dapat dilihat pada Tabel 2, sebagai berikut.

Tabel 2. Hasil Uji Validitas Literasi Keuangan $\left(X_{1}\right)$

\begin{tabular}{lllll}
\hline Item & $\begin{array}{l}\text { Nilai Corrected Item } \\
\text { Total Corrected/r hitung }\end{array}$ & Sig. & rtabel & Kriteria \\
\hline $\mathrm{X}_{1.1}$ & 0,705 & 0,000 & & Valid \\
$\mathrm{X}_{1.2}$ & 0,709 & 0,000 & 0,196 & Valid \\
$\mathrm{X}_{1.3}$ & 0,710 & 0,000 & & Valid \\
$\mathrm{X}_{1.4}$ & 0,457 & 0,000 & & Valid \\
\hline
\end{tabular}

Sumber: Data Penelitian, 2021

Berdasarkan pada hasil analisa tersebut maka keseluruhan pernyataan pada variabel literasi keuangan dapat dinyatakan valid dengan nilai $\mathbf{r}_{\text {hitung }}$ Corrected Item - Total Correlation> dari $\mathrm{r}_{\text {tabel }}$ sebesar 0,196.

Tabel 3. Hasil Uji Validitas Teknologi Sistem Informasi $\left(X_{2}\right)$

\begin{tabular}{lllcl}
\hline Item & $\begin{array}{l}\text { Nilai Corrected Item } \\
\text { Total Corrected/r hitung }\end{array}$ & Sig. & rtabel & Kriteria \\
\hline $\mathrm{X}_{2.1}$ & 0,697 & 0,000 & & \\
$\mathrm{X}_{2.2}$ & 0,730 & 0,000 & 0,196 & Valid \\
$\mathrm{X}_{2.3}$ & 0,731 & 0,000 & & Valid \\
$\mathrm{X}_{2.4}$ & 0,436 & 0,000 & & Valid \\
\hline
\end{tabular}

Sumber: Data Penelitian, 2021

Berdasarkan pada hasil analisa tersebut maka keseluruhan pernyataan pada variabel teknologi sistem informasi dapat dinyatakan valid dengan nilai $\mathbf{r}_{h i t u n g}$ Corrected Item - Total Correlation $>$ dari $r_{\text {tabel }}$ sebesar 0,196.

Tabel 4. Hasil Uji Validitas Pengendalian Internal $\left(X_{3}\right)$

\begin{tabular}{lllll}
\hline Item & $\begin{array}{l}\text { Nilai Corrected Item } \\
\text { Total Corrected/r hitung }\end{array}$ & Sig. & rtabel & Kriteria \\
\hline $\mathrm{X}_{3.1}$ & 0,552 & 0,000 & & Valid \\
$\mathrm{X}_{3.2}$ & 0,652 & 0,000 & & Valid \\
$\mathrm{X}_{3.3}$ & 0,598 & 0,000 & 0,196 & Valid \\
$\mathrm{X}_{3.4}$ & 0,480 & 0,000 & & Valid \\
$\mathrm{X}_{3.5}$ & 0,365 & 0,000 & & Valid \\
\hline
\end{tabular}

Sumber: Data Penelitian, 2021

Berdasarkan pada hasil analisa tersebut maka keseluruhn pernyataan pada variabel pengendalian intern dapat dinyatakan valid dengan nilai $\mathbf{r}_{\text {hitung }}$ Corrected Item - Total Correlation > dari $r_{\text {tabel }}$ sebesar 0,196.

Tabel 5. Hasil Uji Validitas Kualitas Laporan Keuangan (Y)

\begin{tabular}{lllcl}
\hline Item & $\begin{array}{l}\text { Nilai Corrected Item } \\
\text { Total Corrected/r hitung }\end{array}$ & Sig. & r tabel & Kriteria \\
\hline $\mathrm{Y}_{1.1}$ & 0,756 & 0,000 & & Valid \\
$\mathrm{Y}_{1.2}$ & 0,696 & 0,000 & 0,196 & Valid \\
$\mathrm{Y}_{1.3}$ & 0,682 & 0,000 & & Valid \\
$\mathrm{Y}_{1.4}$ & 0,438 & 0,000 & & Valid \\
\hline
\end{tabular}

Sumber: Data Penelitian, 2021

Berdasarkan pada hasil anilisa tersebut maka keseluruhan pernyataan pada variabel kualitas laporan keuangan dinyatakan valid dengan nilai $\mathbf{r}_{\text {hitung }}$ Corrected Item - Total Correlation> dari $\mathrm{r}_{\text {tabel }}$ sebesar 0,196. Uji reliabilitas pada item pernyataan yang sudah dinyatakan valid, maka variabel dapat dinyatakan reliabel 
atau handal apabila jawaban pada kuesioner selalu konsisten. Uji Reliabilitas menggunakan rumus Alpha Cronbach. Hasil Uji reliabilitas pada Tabel 6, sebagai berikut.

Tabel 6. Hasil Uji Realiabilitas

\begin{tabular}{llll}
\hline Variabel & R alpa & R kritis & Kriteria \\
\hline Literasi Keuangan & 0,704 & 0,600 & Reliabel \\
Teknologi Sistem Informasi & 0,620 & 0,600 & Reliabel \\
Pengendalian Intern & 0,720 & 0,600 & Reliabel \\
Kualitas Laporan Keuangan & 0,621 & 0,600 & Reliabel \\
\hline
\end{tabular}

Sumber: Data Penelitian, 2021

Hasil koefisien reliabilitas dengan instrument literasi keuangan adalah sebesar 0,704, dan instrument teknologi sistem informasi adalah sebesar 0,620, serta pengendalian intern adalah sebesar 0,720 dan untuk kualitas laporan keuangan sebesar 0,621, yang artinya bahwa nilai "Alpha Cronbach" > lebih besar dari 0,600, yang artinya keempat instrumen tersebut dinyatakan reliabel atau memenuhi persyaratan. Hasil uji koefisien kurtosis menunjukan bahwa kurve menunjukkan tidak runcing (tinggi) dan juga tidak datar (rendah), sehinggan disimpulkan bahwa informasi/data normal karena memiliki koefisien kurtosis dengan kurve normal.

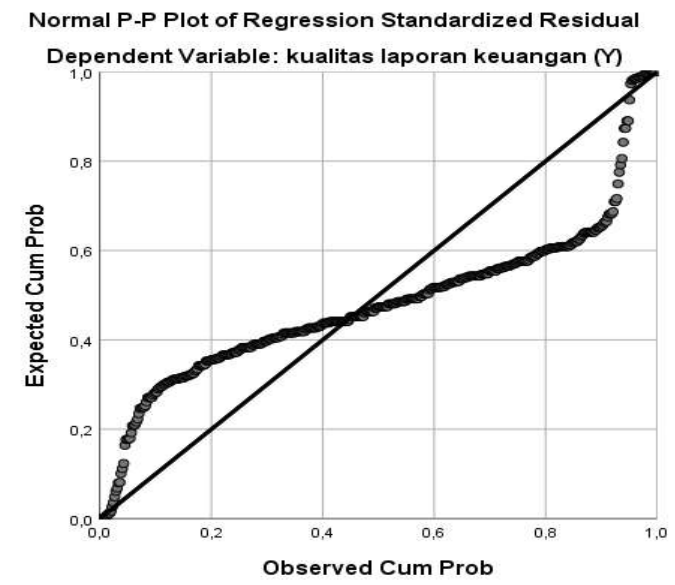

Gambar 1. Hasil Uji Normalitas dengan Koefisien Kurtosis

Sumber: Data Penelitian, 2021

Pada Gambar 1, diperoleh kesimpulan penyebaran data (titik) pada sekitar garis diagonal dan mengikuti arah garis diagonalnya atau grafik, sehingga dinyatakan semua data dapat berdistribusi normal, serta memenuhi pada asumsi normalitas. Uji Multikolinieritas digunakan untuk dapat memastikan tidak terdapat hubungan yang kuat atau tidak ada hubungan linier, di mana hal ini di uji dengan nilai tolerance. Jika nilai tolerance $<0,1$ maka terjadi multikolinearitas.

Tabel 7. Hasil Uji Multikolinieritas

\begin{tabular}{lll}
\hline Variabel Bebas & $\begin{array}{l}\text { Collinearity Statistics } \\
\text { Tolerance }\end{array}$ & VIF \\
\hline Literasi Keuangan & 0,313 & 3,196 \\
Teknologi Sistem Informasi & 0,309 & 3,233 \\
Pengendalian Intern & 0,978 & 1,022 \\
\hline
\end{tabular}

Sumber: Data Penelitian, 2021 
Berdasarkan hasil dari pengujian multikolinearitas, dinyatakan bahwa VIF pada literasi keuangan sebesar 3,196 dan tingkat toleransi sebesar 0,313, sehingga disimpulkan tidak terjadi multikolinearitas dalam variabel independen $\left(\mathrm{X}_{1}\right)$. Berdasarkan hasil dari pengujian multikolinearitas, dinyatakan bahwa VIF pada teknologi sistem informasih akuntansi sebesar 3,233 dan tingkat toleransi sebesar 0,309 , sehingga disimpulkan tidak terjadi multikolinearitas dalam variabel independen $\left(\mathrm{X}_{2}\right)$. Berdasarkan hasil dari pengujian multikolinearitas, dinyatakan bahwa VIF pada pengendalian intern sebesar 1,022 dan tingkat toleransi sebesar 0,978, sehingga disimpulkan bahw tidak terjadi multikolinearitas antara variabel independen $\left(X_{3}\right)$. Uji asumsi heteroskedastisitas bertujuan untuk dapat melihat varian yang tidak sesuai terhadap pengamatan pada sebuah model regresi. Berikut pengujian asumsi heroskedastisitas pada masing-masing variabel.

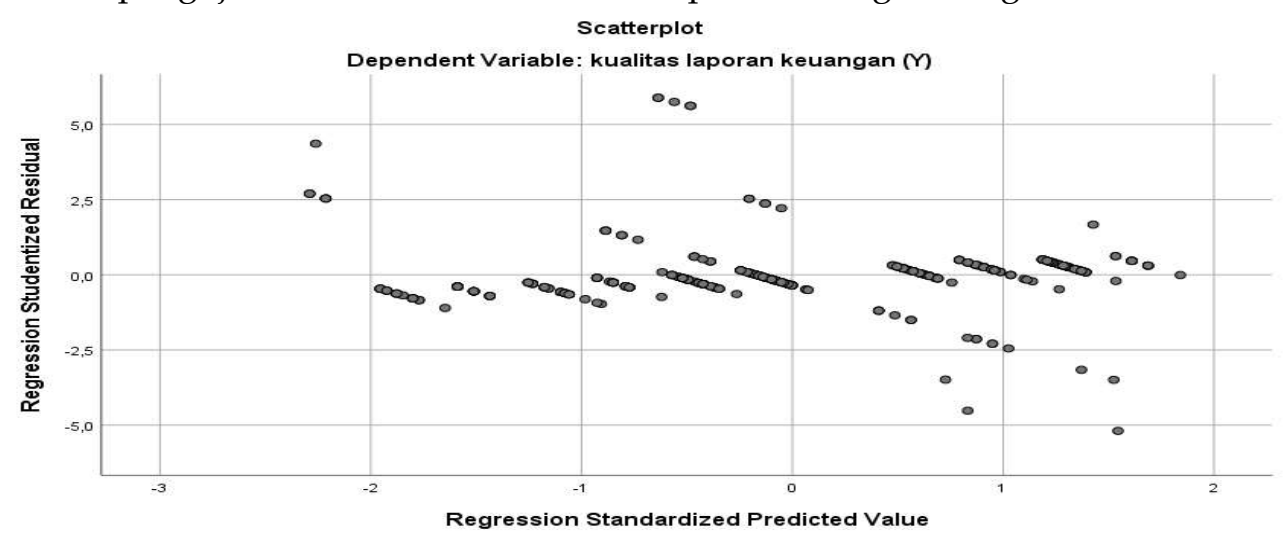

Gambar 2. Uji Asumsi Heteroskedastisitas

Sumber: Data Penelitian, 2021

Berdasarkan pada hasil analisis tersebut, sehingga dapat dikatakan bahwa dalam penyebaran titk-titik akan membentuk sebuah pola yang cukup jelas yang berada diatara sumbuh y dan $\mathrm{x}$. dan dapat dinyatakan bahwa dalam riset ini sama sekali tidak terjadi heteroskedastisitas. Tujuan analisa autokolerasi ini untuk dapat mengetahui sebuah model regresi yang baik. Metode pengujian menggunakan uji Durbin-Watson (DW). Uji asumsi autokorelasi dapat disajikan pada Tabel 8, sebagai berikut ini.

Tabel 8. Hasil Uji Autokorelasi

\begin{tabular}{cccccc}
\hline Model & $R$ & $R$ Squere & $\begin{array}{l}\text { AdjustedR } \\
\text { Squere }\end{array}$ & $\begin{array}{l}\text { Std. Errir of the } \\
\text { Estimate }\end{array}$ & Durbin-Watson \\
\hline 1 & $0,898^{\mathrm{a}}$ & 0,807 & 0,806 & 1,2230 & 1,531 \\
\hline
\end{tabular}

Sumber: Data Penelitian, 2021

Berdasarkan pada hasil analisis tersebut sehingga di simpulkan DurbinWatson 1,531, nilai DW terletak di antara nilai DW < DL $(1.5895<1>783<1.6457)$ hasilnya ditolak sehingga dapat di simpulkan bahwa terjadi autokorelasi dalam regresi ini. Dalam uji hipotesis dapat dilakukan dengan menganalisis regresi berganda yang mana akan menguji pengaruh secara empirik untuk mencari hubungan antara variabel independen terhadap variabel dependen. Hasil pengujian dapat disajikan pada Tabel 9.

Berdasarkan Tabel 9, diperoleh model analisis regresi linier berganda yang digunakan untuk penelitian ini adalah ebagai berikut. 
Tabel 9. Hasil Uji Linier Berganda

\begin{tabular}{|c|c|c|c|c|c|}
\hline & $\begin{array}{l}\text { Unstandardized } \\
\text { Coefficient }\end{array}$ & & $\begin{array}{l}\text { Standardized } \\
\text { Coefficients }\end{array}$ & & \\
\hline Model & B & $\begin{array}{l}\text { Std. } \\
\text { Error }\end{array}$ & Beta & $\mathrm{t}$ & Sig. \\
\hline 1 (Costant) & 1,028 & 0,418 & & 2,457 & 0,014 \\
\hline Literasi Keuangan & 0,155 & 0,037 & 0,159 & 4,225 & 0,000 \\
\hline $\begin{array}{l}\text { Teknologi Sistem } \\
\text { Informasi }\end{array}$ & 0,732 & 0,037 & 00,756 & 19,918 & 0,000 \\
\hline Pengendalian Intern & 0,034 & 0,020 & 0,037 & 1,737 & 0,083 \\
\hline
\end{tabular}

Sumber: Data Penelitian, 2021

Nilai konstan sebesar 1,028 yang menunjukkan bahwa jika literasi keuangan, teknologi sistem informasi dan pengendalian intern diasumsikan bernilai nol, maka pengungkapan emisi karbon akan sebesar 1,028. Nilai koefisien regresi variabel literasi keuangan sebesar 0,155. Koefisien regresi tersebut memiliki nilai positif yang menunjukkan bahwa apabila literasi keuangan meningkat sebesar satu persen maka pengungkapan emisi karbon akan meningkat sebesar 0,155 dengan asumsi variabel lainnya adalah kostan. Nilai koefisien regresi variabel teknologi sistem informasi sebesar 0,732. Koefisien regresi tersebut memiliki nilai positif yang menunjukkan bahwa apabila teknologi sistem informsi meningkat sebesar satu persen maka pengungkapan emisi karbon akan meningkat sebesar 0,732 dengan asumsi variabel lainnya adalah kostan. Nilai koefisien regresi variabel pengendalian intern sebesar 0,034 Koefisien regresi tersebut memiliki nilai positif yang menunjukkan bahwa apabila pengendalian intern meningkat sebesar satu persen maka pengungkapan emisi karbon akan meningkat sebesar 0,155 dengan asumsi variabel lainnya adalah kostan. Berdasarkan hasil analisa koefisien determinasi bertujuan untuk dapat melihat kemampuan variabel independen memberikan sebuah pengaruh terhadap variabel dependen. Hasil dapat disajikan pada Tabel 10, sebagai berikut.

Tabel 10. Ringkasan Hasil Analisis Regresi Berganda

\begin{tabular}{llcllc}
\hline Model & $R$ & $R$ Squere & $\begin{array}{l}\text { Adjusted } R \\
\text { Squere }\end{array}$ & $\begin{array}{l}\text { Std. Errir of the } \\
\text { Estimate }\end{array}$ & Durbin-Watson \\
\hline 1 & $0,898^{\text {a }}$ & 0,807 & 0,806 & 1,2230 & 1,531 \\
\hline
\end{tabular}

Sumber: Data Penelitian, 2021

Berdasarkan analisis pada Tabel 10, dapat disimpulkan bahwa koefisien adjusted R Square sebesar 0,806 atau 80,6 persen variabel kualitas laporan keuangan dapat dijelaskan oleh variable literasi keuangan, teknologi sistem informasi, pengendalian intern, sedangkan 19,4 persen dapat dipengaruhi oleh faktor lain diluar riset ini.

Tabel 11. Hasil Uji Statistik F

\begin{tabular}{lllcll}
\hline Model & Sum of Squares & $\mathrm{df}$ & Mean Square & $\mathrm{F}$ & Sig. \\
\hline 1 Regression & 2701,274 & 3 & 900,425 & 603,679 &, $000^{\mathrm{b}}$ \\
Residual & 645,847 & 433 & 1,492 & & \\
Total & 3347,121 & 436 & & & \\
\hline
\end{tabular}

Sumber: Data Penelitian, 2021

Hasil pengujian uji simultan (F) dapat diketahui bahwa nilai F sebesar 0,000 $<0,05$. Nilai $F_{\text {hitung }} 603,679>\mathrm{F}_{\text {tabel }}$ yaitu 9,403 , dan dapat dikatakan bahwa secara 
bersama-sama variabel independen dapat memberikan pengaruh terhadap variabel dependen.

Tabel 12. Hasil Analisis Uji t

\begin{tabular}{|c|c|c|c|c|c|c|}
\hline \multirow{2}{*}{\multicolumn{2}{|c|}{ Model }} & \multicolumn{2}{|c|}{$\begin{array}{l}\text { Unstandardized } \\
\text { Coefficients }\end{array}$} & \multirow{2}{*}{$\begin{array}{l}\text { Standardized } \\
\text { Coefficients } \\
\text { Beta }\end{array}$} & \multirow[b]{2}{*}{$\mathrm{t}$} & \multirow[b]{2}{*}{ Sig. } \\
\hline & & $\mathrm{B}$ & Std. Error & & & \\
\hline \multirow[t]{4}{*}{$\overline{1}$} & (Constant) & 1,028 & 0,418 & & 2,457 & 0,014 \\
\hline & Literasi Keuangan & 0,155 & 0,037 & 0,159 & 4,225 & 0,000 \\
\hline & $\begin{array}{l}\text { Teknologi Sistem } \\
\text { Informasi }\end{array}$ & 0,732 & 0,037 & 0,756 & 19,918 & 0,000 \\
\hline & Pengendalian Intern & 0,034 & 0,020 & 0,037 & 1,737 & 0,083 \\
\hline
\end{tabular}

Sumber : Data Penelitian, 2021

Pengujian hipotesis koefisien regresi variabel variabel literasi keuangan 0,155 yang berarti bahwa variabel literasi dapat memberikan pengaruh positif pada kualitas laporan keuangan dengan $\mathrm{t}$ hitung 4,225 > t tabel 0,196 serta tingkat signifikan 0,000<0,05, dan dapat dinyatakan bahwa $\mathrm{H}_{1}$ diterima. Pengujian hipotesis koefisien regresi variabel teknologi sistem informasi 0,732 yang berarti variabel teknologi sistem informasi pengaruh yang positif pada kualitas laporan keuangan. Sehingga dapat dibuktikan dengan thitung 19,918 > t tabel 0,196 serta tingkat signifikan $0,000<0,05$, dan dapat dinyatakan bahwa $\mathrm{H}_{2}$ diterima. Pengujian hipotesis koefisien regresi variabel variabel pengendalian internal 0,034 yang berarti bahwa variabel pengendalian intern dapat memberikan sebuah pengaruh namun tidak signifikan pada kualitas laporan keuangan, dapat dibuktikan dengan $t_{\text {hitung }} 1,737>t_{\text {tabel }} 0,196$ serta tingkat signifikan $0,083>0,05$, dan dapat dinyatakan bahwa $\mathrm{H}_{3}$ diterima.

Hasil riset menunjukan Literasi keuangan pengaruh positif dan signifikan terhadap kualitas laporan keuangan. Hal ini dapat dibuktikan dengan $t_{\text {hitung }} 4,225$ $>t_{\text {tabel }}$ 0,196 ini menunjukkan semakin tinggi literasi keuangan maka akan meningkatkan kualitas laporan keuangan. Riset yang dilakukan sesuai dengan penelitan oleh Wijangka, (2018). Dengan kemampuan pemilik UMKM akan literasi dapat memberikan kekuatan bagi para pemilik UMKM di kabupaten pasuruan agar dapat mengelolah keuangan secara tepat dan efisien guna terhindar dari kebangkrutan usaha.

Teknologi sistem informasi berpengaruh positif dan signifikan terhadap kualitas laporan keuangan. Pada variabel teknologi sistem informasi akuntansi mempunyai $t_{\text {hitung }} 0,732>t_{\text {tabel }} 0,196$. Hasil ini menunjukkan bahwa tingginya pemahaman teknologi sistem informasi akan dapat meningkatkan kualitas laporan keuangan. Riset ini sejalan dengan penelitian yang dilakukan oleh Samukri, (2020) menyatakan bahwa sistem informasi akuntansi serta kualitas laporan keuangan terdapat hubungan sehingga mendukung hipotesis. Dengan kemampuan akan teknologi yang dimiliki oleh pengusaha UMKM, tentunya akan sangat membantu UMKM dalam menghadapi persaingan yang begitu ketat terutama dalam era revolusi indutri 4.0 ini.

Pengendalian internal pengaruh positif namum tidak signifikan terhadap kualitas laporan keuangan. Pada variabel pengendalian internal mempunyai $t_{\text {hitung }}$ $1,737>t_{\text {tabel }} 0,196$ dengan tingkat signifikansi sebesar 0.083 . Hasil ini menunjukkan bahwa pemahaman pengendalia intern akan dapat meningkatkan kualitas 
laporan keungan namum dianggap tidak signifikan bagi UMKM. Riset ini mendukung terhadap riset yang di lakukan oleh Rahmawati et al., (2018) yang menyatakan bahwa sistem pengendalian intern berpengaruh positif terhadap kualitas laporan keuangan. Pada UMKM Pengendalin intern dianggap dapat mempengaruhi akan kualitas laporan keuangan, namum tidak signifikan hal ini dikarenakan ketidakpahaman pelaku UMKM akan begitu pentingnya pengendalian intern guna mempertahakan keamanan akan asset dari UMKM. menggap bahwa pengendalian intern hanya pada perusahaan yang besar, karena bagi UMKM cukup dengan adanya teknologi sistem informasi semua sudah bisa dikendalikan.

\section{SIMPULAN}

Literasi keuangan berpengaruh terhadap kualitas laporan keuangan, sehingga dapat diasumsikan bahwa ketika literasi keuangan sesuai dengan harapan yang diinginkan maka hal tersebut akan berdampak baik pada pertumbuhan UMKM. Teknologi sistem informasi berpengaruh terhadap kualitas laporan keuangan, sehingga jika ada pengaruh antara teknologi sistem informasi akuntansi pada kualitas laporan keuangan maka hal tersebut menunjukan bahwa Teknologi informasi telah menjadi sumber daya bisnis yang penting karena tujuan terbesar teknologi informasi terhadap akuntansi adalah kemampuan untuk mengembangkan dan menggunakan sistem terkomputerisasi di era revolusi 4.0

Sistem pengendalian intern yang efektif bertujuan untuk membatasi tingkat risiko kehilangan asset pada sebuah UMKM. Pengendalian intern berpengaruh terhadap kualitas laporan keuangan, namum tidak signifikan sehingga dapat disimpulkan apabila para UMKM agar mampu bertahan di dalam era revolusi indutri 4.0 dan agenda PBB tahun 2030 tentunya diharapkan agar UMKM mampu menjaga kualitas laporan keuangan dengan literasi keuangan, teknologi sistem informasi. Untuk penelitian selanjutnya disarankan untuk menganalisis lebih mendalam lagi tentang pengaruh literasi keuangan, teknologi sistem informasi khususnya pada pengendalian intern terhadap kualitas laporan keuangan.

\section{REFERENSI}

Aditya, O. R., \& Surjono, W. (2017). Pengaruh Sistem Pengendalian Intern Terhadap Kualitas Laporan Keuangan. Jurnal SIKAP (Sistem Informasi, Keuangan, Auditing Dan Perpajakan). https://doi.org/10.32897/sikap.v2i1.64

Anggraeni, B. D. (2015). Pengaruh Tingkat Literasi Keuangan Pemilik Usaha. Jurnal Vokasi Indonesia.

Aniftahudin, A., Kamaliah, K., \& Hanif, R. (2016). Pengaruh Pemahaman Akuntansi, Sistem Akuntansi Keuangan Pemerintah Daerah Dan Teknologi Informasi Terhadap Kualitas Laporan Keuangan Pemerintah Daerah (Studi pada skpd Kabupaten Indragiri Hilir). Jurnal Online Mahasiswa Fakultas Ekonomi Universitas Riau.

Aribawa, D. (2016). Pengaruh literasi keuangan terhadap kinerja dan keberlangsungan UMKM di Jawa Tengah. Jurnal Siasat Bisnis. https://doi.org/10.20885/jsb.vol20.iss1.art1

Arikunto. (2010). Suharsimi Arikunto.pdf. In Prosedur Penelitian Suatu Pendekatan Praktik-Revisi ke X. 
Costello, A. M., \& Regina, R. (2011). The Impact of Financial Reporting Quality on Debt Contracting: Evidence from Internal Control Weakness Reports. Journal of Accounting Research. https://doi.org/10.1111/j.1475-679X.2010.00388.x

Dandago, K. I., \& Rufai, A. S. (2014). Information technology and accounting information system in the Nigerian banking industry. Asian Economic and Financial Review.

Faishol, A., \& Lamongan, U. I. (2016). Pengaruh Sistem Pengendalian Internal Terhadap Kualitas Laporan Keuangan (Studi kasus Pada Satuan Kerja Perangkat Daerah Pemerintah Kabupaten Lamongan). Jurnal Penelitian Ekonomi Dan Akuntansi.

Gasperz, J. J. (2019). Pengaruh Kompetensi Sumber Daya Manusia, Sistem Pengendalian Intern, dan Pemanfaatan Teknologi Informasi terhadap Kualitas Laporan Keuangan (Studi pada Badan Pusat Statistik Wilayah Maluku). JBMP (Jurnal Bisnis, Manajemen Dan Perbankan). https://doi.org/10.21070/jbmp.v5i2.2550

Ghasemi, M., Shafeiepour, V., Aslani, M., \& Barvayeh, E. (2011). The impact of information technology (it) on modern accounting systems. Procedia - Social and Behavioral Sciences. https:// doi.org/10.1016/j.sbspro.2011.11.023

Gupta, K., \& Kaur, J. (2014). A Study of Financial Literacy Among Micro Entrepreneurs In District Kangra. International Journal of Research in Business Management.

Gusherinsya, R., \& Samukri, S. (2020). Pengaruh Penerapan Sistem Informasi Akuntansi Terhadap Kualitas Laporan Keuangan. JURNAL AKUNTANSI. https://doi.org/10.37932/ja.v9i1.94

Hanifah, S., Sarpingah, S., \& Putra, Y. (2020). The Effect of Level of Education, Accounting Knowledge, and Utilization Of Information Technology Toward Quality The Quality of MSME's Financial Reports. https://doi.org/10.4108/eai.3-2-2020.163573

Hatammimi, J., \& Krisnawati, A. (2018). Financial literacy for entrepreneur in the industry 4.0 era: A conceptual framework in Indonesia. ACM International Conference Proceeding Series. https:/ / doi.org/10.1145/3285957.3285985

McDaniel, L., Martin, R. D., \& Maines, L. A. (2002). Evaluating financial reporting quality: The effects of financial expertise vs. financial literacy. Accounting Review. https:// doi.org/10.2308/accr.2002.77.s-1.139

Moses Bukenya. (2012). Internal controls and access to commercial loan financing for small scale enterprises in Uganda. African Journal Of Business Management. https://doi.org/10.5897/ajbm11.2757

Mosteanu, N. R., \& Faccia, A. (2020). Digital systems and new challenges of financial management - fintech, XBRL, blockchain and cryptocurrencies. Quality - Access to Success.

Muda, I., Wardani, D. Y., Erlina, Maksum, A., Lubis, A. F., Bukit, R., \& Abubakar, E. (2017). The influence of human resources competency and the use of information technology on the quality of local government financial report with regional accounting system as an intervening. Journal of Theoretical and Applied Information Technology.

Mukoffi, A., \& Sulistiyowati, Y. (2019). The Role of Financial Accounting Standards for Small And Medium Micro Economic Sectors: Case Studies In Lowokwaru 
District, Malang. International Journal of Research in Business and Social Science. https://doi.org/http://dx.doi.org/10.20525/ijrbs.v8i3.202

Putra, Y. M. (2018). Pemetaan Penerapan Standar Akuntansi Keuangan Emkm Pada Umkm Di Kota Tangerang Selatan. Jurnal Profita. https://doi.org/10.22441/profita.2018.v11.02.004

Rahmawati, A., Mustika, I. W., \& Eka, L. H. (2018). Pengaruh Penerapan Standar Akuntansi Pemerintah, Pemanfaatan Teknologi Informasi, Dan Sistem Pengendalian Intern Terhadap Kualitas Laporan Keuangan SKPD Kota Tangerang Selatan. Jurnal Ekonomi, Bisnis, Dan Akuntansi (JEBA).

Rahmawati, T., \& Puspasari, O. R. (2017). Implementasi Sak Etap Dan Kualitas Laporan Keuangan Umkm Terkait Akses Modal Perbankan. Jurnal Kajian Akuntansi. https://doi.org/10.33603/jka.v1i1.510

Rumbianingrum, W., \& Wijangka, C. (2018). Pengaruh Literasi Keuangan Terhadap Pengelolaan Keuangan UMKM. Jurnal Manajemen Dan Bisnis (ALMANA).

Suárez, C. A. (2017). Internal Control Systems Leading To Family Business Performance In Mexico: A Framework Analysis. Journal of International Business Research.

Sucuahi, W. T. (2013). Determinants of Financial Literacy of Micro Entrepreneurs in Davao City. International Journal of Accounting Research. https://doi.org/10.12816/0001127

Sularsih, H., \& Nasir, A. (2020). Strategi Usaha Mikro Kecil Dan Menengah (Umkm) Dalam Menghadapi Era Revolusi Industri 4.0 Di Kabupaten Pasuruan. Referensi: Jurnal Ilmu Manajemen dan Akuntansi, 8(2), 65-73.

Van Caneghem, T., \& Van Campenhout, G. (2012). Quantity and quality of information and SME financial structure. Small Business Economics. https://doi.org/10.1007/s11187-010-9306-3

Vander Bauwhede, H., De Meyere, M., \& Van Cauwenberge, P. (2015). Financial reporting quality and the cost of debt of SMEs. Small Business Economics. https:/ /doi.org/10.1007/s11187-015-9645-1

Widarsono, A. (2013). Pengaruh Efektivitas Penerapan Teknologi Informasi Terhadap Kualitas Laporan Keuangan Pemerintah Daerah. Jurnal Riset Akuntansi Dan Keuangan. https://doi.org/10.17509/jrak.v1i1.6566

Yang, L., \& Zhang, Y. (2020). Digital financial inclusion and sustainable growth of small and micro enterprises-evidence based on China's new third board market listed companies. Sustainability (Switzerland). https://doi.org/10.3390/su12093733 